\title{
The Importance of Fluorine in the Life Science Industry
}

\author{
Peter Maienfisch and Roger G. Hall
}

\begin{abstract}
Fluorine-containing compounds are at the leading edge of many new developments in the life science industry. In recent years a steady increase in the number of fluorinated organic molecules reaching commercial status as crop protection products and pharmaceutical drugs has been observed: in 1978, ca. 600 pesticides were known, but only approximately 25 (4\%) contained fluorine. Today, fluorine-containing compounds account for more than $17 \%$ of all commercially available crop protection agents and many others are currently under development. The structures of the fluorine-containing development compounds proposed for ISO common names between 1997 and 2002 are highlighted in this paper. In the pharmaceutical area around 220 fluorinated drugs were on the market in 1990, representing ca. $8 \%$ of all synthetic drugs. Six years later already more than 1500 fluorine-containing drugs were under development. Fluorine-containing compounds have also been successful in the marketplace, such as the insecticides fipronil and lambda-cyhalothrin, the fungicides epoxiconazole and trifloxystrobin, the herbicides trifluralin and clodinafop, and the pharmaceutical blockbusters Fluoxetine (Prozac ${ }^{\circledR}$ ), Paroxetine $\left(\right.$ Paxil $\left.^{\circledR}\right)$, Ciprofloxacin (Cipro $\left.{ }^{\circledR}\right)$ and Cisaprid (Propulsid $\left.{ }^{\circledR}\right)$. This success is mainly due to the fact that selectively fluorinated compounds can exhibit dramatically improved potency when compared to the non-fluorinated analogues. The incorporation of fluorine into a biologically active compound alters the electronic, lipophilic and steric parameters and can critically increase the intrinsic activity, the chemical and metabolic stability, and the bioavailability. The positive effects of fluorine on the biological efficiency is outlined by three examples: in the chemical class of herbicidal thiatriazines, the presence or the absence of fluorine leads to dramatic effects on the biological activity; the metabolic stability and the pharmacokinetics of aminopyrazinone acetamide thrombin inhibitors were improved by the introduction of fluorine, and in a novel class of insecticides/acaricides any modification of the gem-difluorovinyl group results in a strong decrease of biological activity.
\end{abstract}

Keywords: Aminopyrazinone acetamides · Biological activity · Crop-protection agents ·

Development compounds · gem-Difluorovinyl derivatives · Fluorine · Fluorine-containing compounds ·

Pharmaceutical drugs · Thiatriazines

\section{Introduction}

In recent years many selectively fluorinated analogues of biologically active compounds have been found that exhibit dramatically improved potency when compared to the non-fluorinated analogues [1]. These findings have sparked an enormous interest in fluorinated organic molecules in the life science industry and have resulted in a steady increase in the number of such molecules reaching commercial status as crop protection products and pharmaceutical drugs. This development has been facilitated by the significant progress in fluoroorganic chemistry over the last three decades: new fluorine-containing building blocks have become available and novel synthetic methods and fluorination reagents have been developed that facilitate the introduction of fluorine or fluorine-containing units into organic molecules [2].

This article concentrates on recent developments in fluorine-containing crop protection agents and reviews the important role of fluorine in the life science industry.

\section{Fluorinated Crop Protection Products}

Chemical crop protection agents continue to play the major role in safeguarding crops against damage by pest and diseases, or loss through weed competition. New molecules are continually being sought with improved biological activity, new modes of action, reduced environmental impact and improved user safety. Crop protection agents containing fluorine figure prominently in this quest.

In $1978, c a .600$ pesticides were known, but only approximately 25 (4\%) contained fluorine [3]. Today, more than $17 \%$ of all commercially available crop protection agents contain fluorine and this number looks set to increase (Table) [4-7]. When a

company has successfully optimised a
Optimisation Chemistry

Syngenta Crop Protection AG

Schwarzwaldallee 215

Tel.: + 41613236647

Fax: + 41613238529

E-Mail: peter.maienfisch@syngenta.com 
Table. History of fluorinated crop protection compounds

\begin{tabular}{lcccc} 
Year & $\begin{array}{c}\text { Total number } \\
\text { of comp. }\end{array}$ & \multicolumn{2}{l}{ Fluorine-containing } & Reference \\
\cline { 3 - 4 } & Number & [\%] & \\
\hline 1978 & ca. $600^{\mathrm{a}}$ & 25 & $4 \%$ & G.T. Newbold [3] \\
\hline 1988 & - & - & $8.5 \%$ & Agrochemical Handbook 2 ${ }^{\text {nd }}$ Ed. [4] \\
1999 & ca. $700^{\text {b }}$ & 122 & $17 \%$ & Enigma Marketing Research, 1999 [5] \\
\hline a known pesticides & b market products & & \\
\hline
\end{tabular}

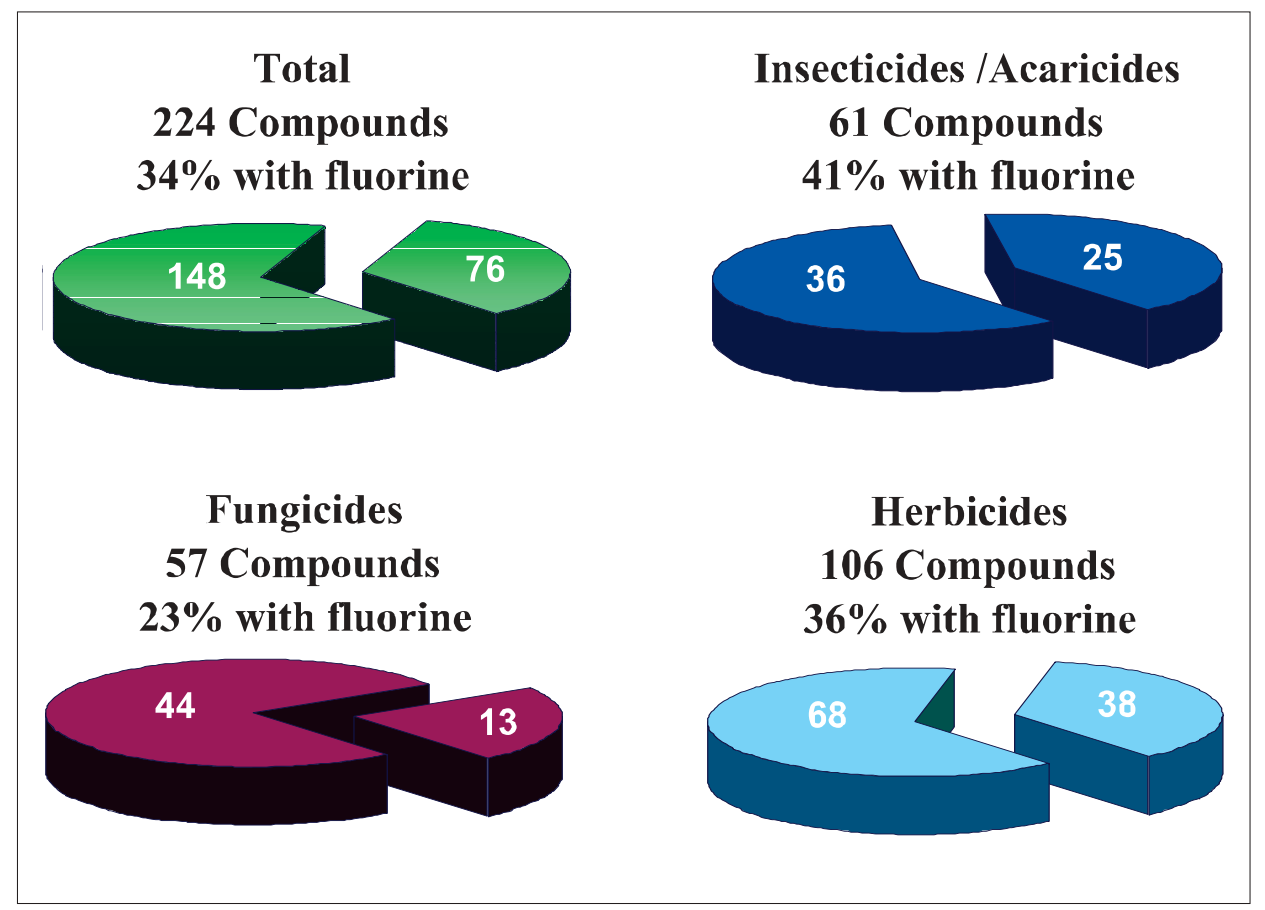

Fig. 1. Fluorine-containing crop protection compounds proposed for ISO common names between 1990 and 2002 - compounds per indication

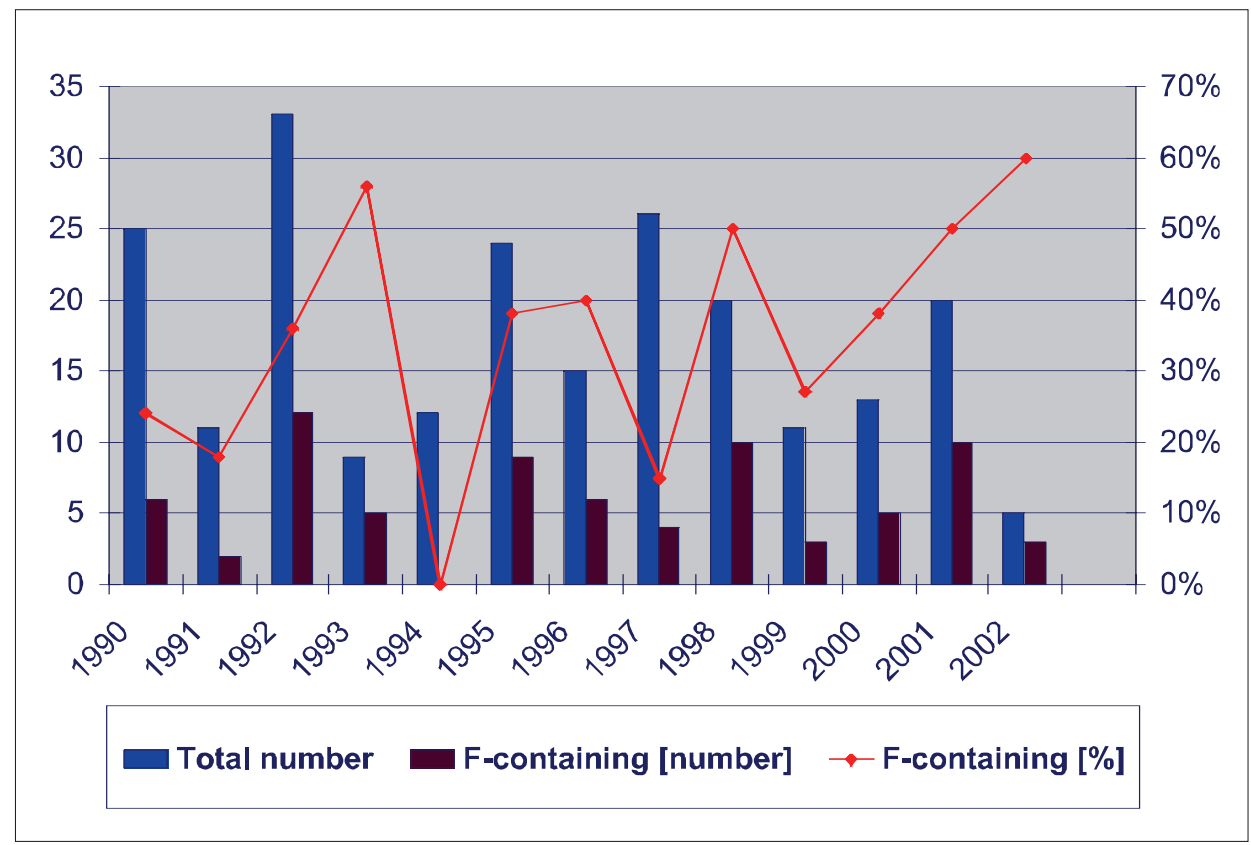

Fig. 2. Fluorine-containing crop protection compounds proposed for ISO common names between 1990 and 2002 - compounds per annum chemical class and identified a development compound, at some stage during development, a ISO common name must be agreed. During the period 1990-2002, a total of 224 compounds were filed for common name approval (Fig. 1 and 2). An analysis of these structures reveals that of the $224,76(34 \%)$ contain at least one fluorine atom. Interestingly, there is quite a difference between the three indications; amongst insecticides/acaricides 25 from 61 compounds $(41 \%)$ contain fluorine; within fungicides only 13 from 57 compounds $(23 \%)$ and herbicides 38 from 105 compounds $(36 \%)$ contain fluorine.

Let us now concentrate on some recent developments. Examples of fluorine-containing insecticides, fungicides and herbicides proposed for ISO common names between 1997 and 2002 are shown in Fig. 3-5. In the majority of cases, these molecules represent the latest developments from established chemical or mode of action classes:

\section{Insecticides/Acaricides (Fig. 3)}

- Benzoylureas (mode of action: chitin biosynthesis): noviflumuron, bistrifluron

- Pyrethroids (mode of action: voltagegated $\mathrm{Na}$ channel): profluthrin, metofluthrin, protrifenbute

- Pyrazoles/Fipronil analogues (mode of action: GABA-gated $\mathrm{Cl}$ channel): ethiprole, acetoprole

- Strobilurines (mode of action: mitochondrial respiration - complex III): fluacrypyrim

- Aminopyrimidines (mode of action: mitochondrial respiration - complex I): flufenerim

\section{Fungicides (Fig. 4)}

- Strobilurines (mode of action: mitochondrial respiration - complex III): picoxystrobin, trifloxystrobin, fluoxastrobin

- Triazoles (mode of action: sterol biosynthesis): simeconazole

- Cinnamic acids (mode of action: unknown, effects on cell wall postulated): flumorph

\section{Herbicides (Fig. 5)}

- Acetolactate synthase (ALS) inhibitors: flucarbazone, tritosulfuron, trifloxysulfuron-sodium, penoxsulam, flucetosulfuron, florasulam

- Protoporphyrinogen oxidase (PPGO) inhibitors: butafenacil, benzfendizone, flufenpyr-ethyl, profluazol

- Fatty acid biosynthesis inhibitors: flufenacet, metamifop

- Phytoene desaturase inhibitors: picolinafen, beflubutamid

In other cases, new chemical classes with new, or unknown modes of action are 


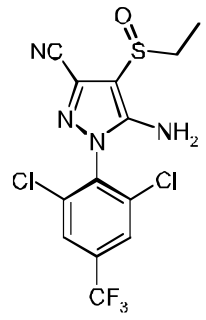
Ethiprole
(Bayer / Aventis)<smiles>FC(F)(F)c1ccc(OCCCOc2c(Cl)cc(OCC=C(Cl)Cl)cc2Cl)nc1</smiles><smiles>COC(=O)c1cc(Cl)ccc1NS(=O)(=O)C(F)(F)F</smiles><smiles>CO/C=C(/C(=O)OC)c1ccccc1COc1cc(C(F)(F)F)nc(OC(C)C)n1</smiles><smiles></smiles>
(Dow)<smiles>C/C=C/C1C(C(=O)OCc2c(F)c(C)c(C)c(F)c2F)C1(C)C</smiles><smiles>C/C=C/C1C(C(=O)OCc2c(F)c(F)c(COC)c(F)c2F)C1(C)C</smiles>

Profluthrin (Sumitomo)

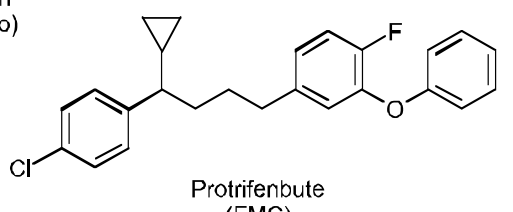

(FMC)

Fig. 3. Fluorine-containing insecticides and acaricides proposed for ISO common names between 1997 and 2002

appearing. Such new classes are important additions to the established crop protection solutions; in several indications, nature has developed resistance to certain established chemistries, and new modes of action can help reduce the threat that resistance can have on the farmer' crop yield. As examples of such novel chemistries the insecticides indoxacarb, flonicamid and pyridalyl as well as the fungicides benthiavalicarb and cyflufenamid should be mentioned.

The fluorine-containing compounds listed in Fig. 3-5 possess improved properties compared to their non-fluorinated parents. These properties can include increased intrinsic activity, lower dosage, longer duration of action, lower toxicity, increased selectivity and, conversely, broader spectrum of activity.

It is assumed that for most of these compounds improved pharmacokinetics (uptake and/or distribution) or greater metabolic stability is responsible for their superiority compared to the non-fluorinated parents. In some cases fluoro-containing groups were found to be critical for excellent biological activity and it is believed that the intrinsic activity is also enhanced:

- the 4-trifluoromethyl-pyridyl group in flonicamid

- the 2,6-difluorophenyl group in benzoylureas
- the trifluoromethyl sulfonyl group in amidoflumet

- the trifluoromethyl group in flufenacet, picolinafen and beflubutamid

Fluorine-containing crop-protection products have also been successful in the marketplace. According to data from Phillips McDougall in each indication two fluorine-containing products are among the 15 best selling compounds (Fig. 6). These are the insecticides fipronil and lambda-cyhalothrin, the fungicides epoxiconazole and trifloxystrobin and the herbicides trifluralin and clodinafop, all achieving sales between 90 and 270 Mio \$ in 2001.

\section{Fluorinated Pharmaceutical Drugs}

In the pharmaceutical area many fluorinated compounds with outstanding activity and properties have been very successfully introduced to the market in almost all indications. These include, for example, antidepressants, anti-inflammatory agents, antimalaria compounds, antipsychotic drugs, antiviral agents, steroids and anaesthetics [8-10].

By 1990 around 220 fluorinated drugs were on the market, representing $\mathrm{ca}$. $8 \%$ of all synthetic drugs. Six years later already more than 1500 fluorine-containing drugs were described to be under development [11]. In 1997, 27 drugs each generated more than 1 billion $\$$ of sales. Among these, four compounds contain at least one fluorine atom. These are the antidepressants Fluoxetine (Prozac ${ }^{\circledR}$ ) and Paroxetine (Paxil $\left.{ }^{\circledR}\right)$, the antibacterial agent Ciprofloxacin $\left(\right.$ Cipro $\left.^{\circledR}\right)$ and the peristaltic stimulant Cisaprid (Propulsid ${ }^{\circledR}$ ) [12] (Fig. 7).

\section{The Unique Features of Fluorine}

The importance of fluorine in the life sciences industry can mainly be attributed to the following features [2][9][13-14].

- The substitution of a hydrogen atom by a fluorine atom is one of the most commonly applied classical bioisosteric replacements (for general reviews on bioisosterism: see [15-17]). Fluorinated compounds usually have a sufficient similarity in size and shape (Van der Waals radius: $1.47 \AA$ for $\mathrm{F}, 1.20 \AA$ for $\mathrm{H}$ ) to their non-fluorinated analogues allowing a fit to a given target site.

- The carbon-fluorine bond is relatively strong (485 $\mathrm{KJ} \mathrm{mol}^{-1}$ compared to 416 $\mathrm{KJ} \mathrm{mol}^{-1}$ for the $\mathrm{C}-\mathrm{H}$ bond). Therefore, fluorinated compounds tend to be more resistant to metabolic degradation. In addition, the presence of fluorine generally also strengthens all nearby bonds [18-19]. 


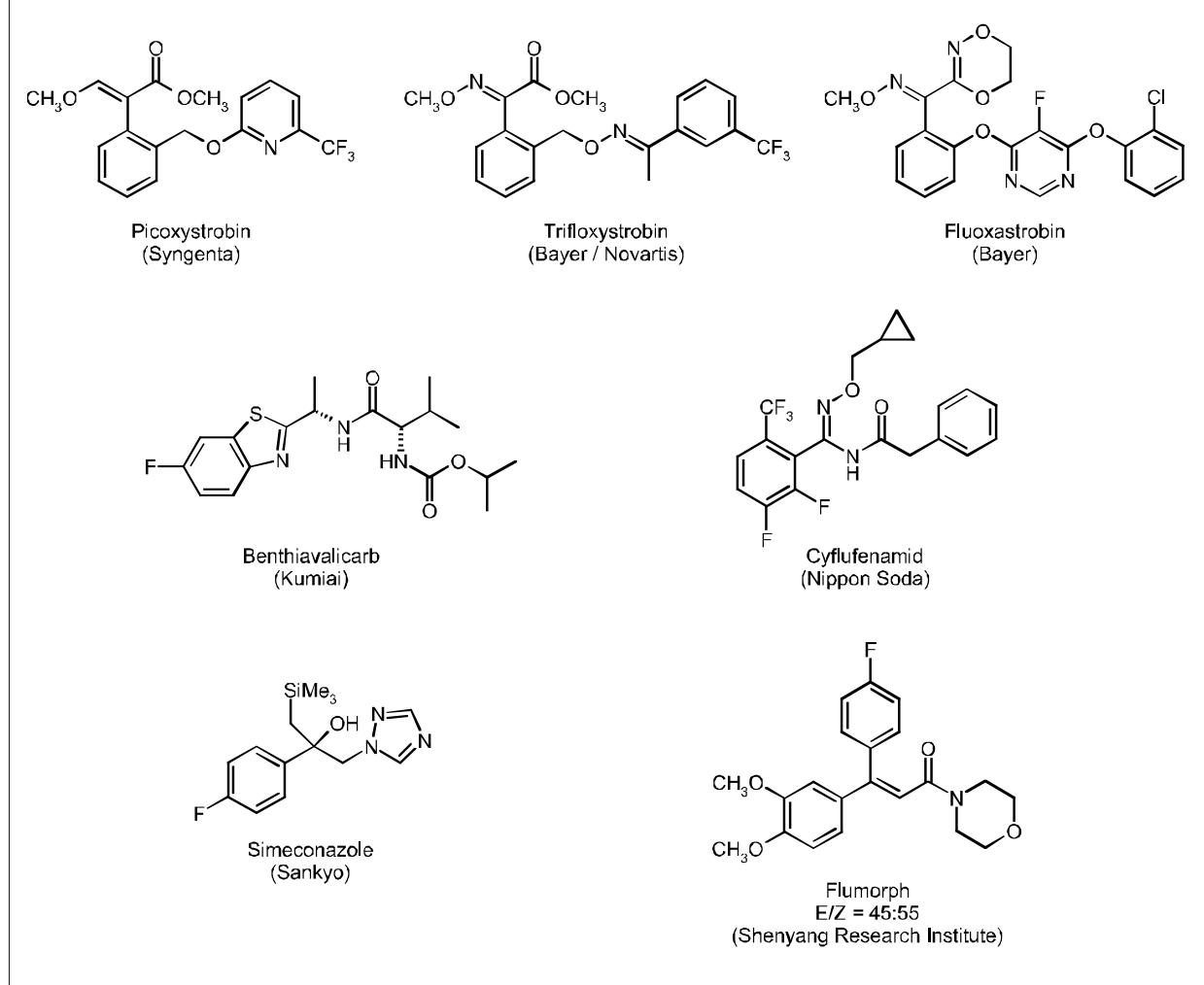

Fig. 4. Fluorine-containing fungicides proposed for ISO common names between 1997 and 2002
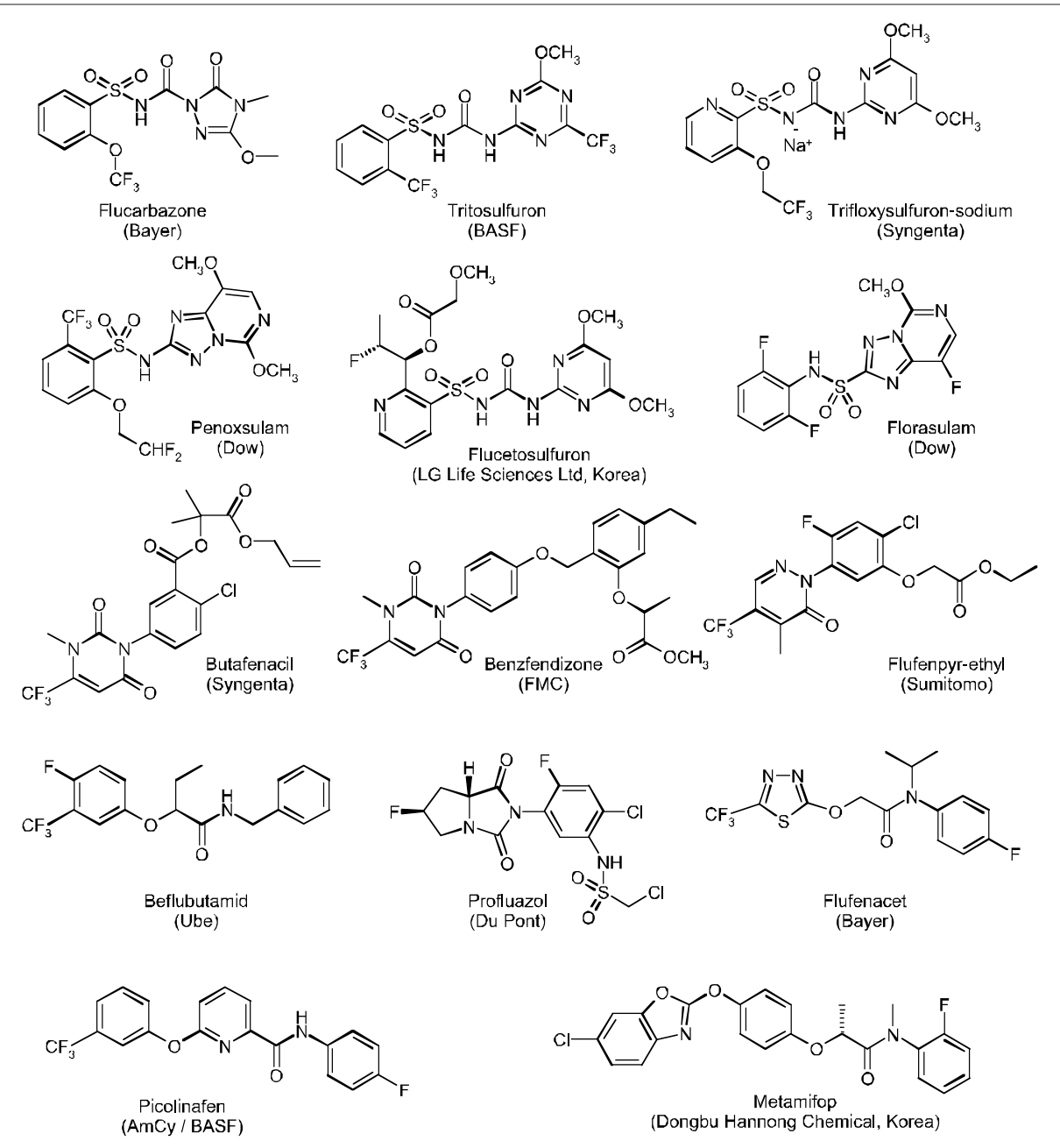

Fig. 5. Fluorine-containing herbicides proposed for ISO common names between 1997 and 2002
- Replacement of hydrogen by fluorine enhances lipophilicity, with functional groups such as $\mathrm{CF}_{3}, \mathrm{CF}_{3} \mathrm{O}$ and $\mathrm{CF}_{3} \mathrm{~S}$ being amongst the most lipophilic groups known. This may result in a different pharmacokinetic behaviour such as enhanced passive diffusion of compounds across membranes. For example, many compounds acting on the central nervous system (CNS) contain a fluorophenyl group or a $\mathrm{CF}_{3}$ group, which contributes to the overall pharmacological activity by enhancing CNS penetration.

- The high electronegativity of fluorine (4.0 vs. 2.1 for $\mathrm{H}$ ) frequently alters electronic effects and chemical reactivity. This may result in enhanced intrinsic activity as well as in a different chemical behaviour.

\section{Effect of Fluorine on Biological Activity}

As shown in the previous paragraphs fluorinated compounds have very important applications in the life science industry. The incorporation of fluorine into a biologically active compound can simultaneously influence the electronic, lipophilic and steric parameters and can therefore, in the ideal case, critically increase the intrinsic activity and the chemical and metabolic stability but also improve the pharmacokinetics.

The positive effects of fluorine on the biological activity have already been reviewed in many publications e.g. [1][2][9][14][16] and literature cited therein and is further demonstrated by the following three examples.

\subsection{Herbicidal Thiatriazines}

The thiatriazines (Fig. 8) are an experimental class of herbicide that display an interesting activity on grasses and broadleaf weeds, and importantly have a good crop tolerability [20][21]. Within this class, the presence or absence of fluorine has a significant effect on the biological activity. Without fluorine, the 'naked phenoxy' compound CGA 288'821 shows no control of grasses (echinochloa, digitaria) and broadleaf weeds (stellaria, chenopodium); introducing two fluorine atoms improves activity, but a tremendous jump in control of these weeds is achieved with the pentafluoro-phenoxy compound CGA 325'615, as shown in Fig. 9.

\subsection{Aminopyrazinone Acetamides as Novel Thrombin Inhibitors}

Recently Merck researchers succeeded to improve the metabolic stability and the pharmacokinetics of a novel thrombin inhibitor lead by the introduction of fluorine. 
<smiles>N#Cc1nn(-c2c(Cl)cc(C(F)(F)F)cc2Cl)c(N)c1S(=O)S(F)(F)F</smiles>

Fipronil

Aventis / Bayer

Launch: 1993

Chemical Class: Pyrazole

Sales 2001: $\quad 270$ Mio \$

Rank:

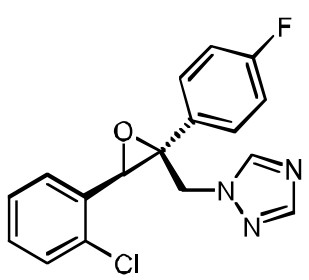

Epoxiconazole BASF

Launch: 1993

Chemical Class: Triazole

Sales 2001: 215 Mio \$

Rank:

4

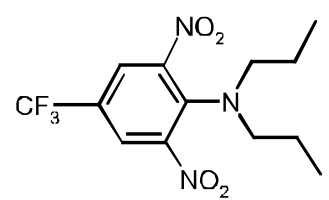

Herbicides

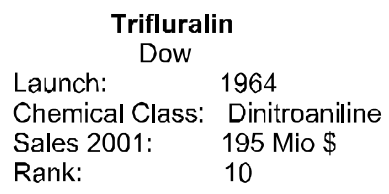

Fungicides

\section{Insecticides}<smiles>CC1(C)[C@@H](C=C(Cl)C(F)(F)F)[C@H]1C(=O)O[C@H](C#N)c1cccc(Oc2ccccc2)c1</smiles><smiles>CO/N=C(/C(=O)OC)c1ccccc1CO/N=C(\C)c1cccc(F)c1</smiles>

\begin{tabular}{ll}
\multicolumn{2}{c}{$\begin{array}{c}\text { Trifloxystrobin } \\
\text { Bayer }\end{array}$} \\
Launch: & 2000 (Novartis) \\
Chemical Class: & Strobilurin \\
Sales 2001: & 90 Mio $\$$ \\
Rank: & 15
\end{tabular}<smiles>C#CCOC(=O)[C@H](C)Oc1ccc(Oc2ncc(Cl)cc2F)cc1</smiles>

$$
\begin{array}{ll}
\multicolumn{2}{c}{\begin{array}{c}
\text { Clodinafop } \\
\text { Syngenta }
\end{array}} \\
\text { Launch: } & 1991 \\
\text { Chemical Class: } & \text { Aryloxypropionate } \\
\text { Sales 2001: } & 180 \text { Mio \$ } \\
\text { Rank: } & 12
\end{array}
$$

Fig. 6. Fluorine-containing products among the 15 best-selling insecticides, fungicides and herbicides (Data from Phillips McDougall)
The aminopyrazinone acetamide lead $\mathbf{1}$ (Fig. 10) has been found to be a very potent thrombin inhibitor; however, its persistence was not satisfactory. Studies revealed three principal sites of metabolism: oxidation at the benzylic position, oxidation of the methyl group attached to the pyrazinone ring and conjugation of the aminopyridyl group. Applying a 'metabolism-directed optimisation process' resulted in the synthesis of compound $\mathbf{2}$ with strongly improved oral bioavailability and plasma half-lives. The introduction of a $\mathrm{CF}_{2}$-group at the benzylic position as well as the replacement of the aminopyridyl group by a fluoropyridyl moiety were essential to achieve this improvement. Further modifications directed towards the improvement of the aqueous solubility ('pharmacokinetic optimisation') led to the discovery of the $\mathrm{N}$-oxide $\mathbf{3}$, which has recently advanced into Phase I clinical trials [22][23].

\section{3. gem-Difluorovinyl Derivatives with Insecticidal and Acaricidal Ac- tivity}

The unique role of fluorine as part of a gem-difluorovinyl pharmacophore has been demonstrated by Pitterna et al. [24]. gem-Difluorovinyl derivatives of the general structure 4 (Fig. 11) are inhibitors of the $\beta$-oxidation of fatty acids in insect mitochondria and possess excellent insecticidal and acaricidal activity. Optimisation of the original lead 5 led to the discovery of CGA 304'111. This compound has a favourable toxicological profile and exhibits excellent activity and good persistence in field trials against a wide rage of pests such as mites, aphids, scales, thrips and jassids.

In this chemical class many modifications of the gem-difluorovinyl pharmacophore have been investigated. Surprisingly, all variations led to inactive compounds with the exception of the gem-dichlorovinyl analogue which possesses some weak insecticidal activity (Fig. 12).

\section{Conclusions}

Fluorine-containing compounds are at the leading edge of many new developments in the life science industry. In recent years a steady increase in the number of fluorinated organic molecules reaching com- 
<smiles>CNCCC(Oc1ccc(C(F)(F)F)cc1)c1ccccc1</smiles>

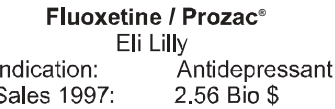
$\begin{array}{ll}\text { Sales 1997: } & 2.56 \text { Bio } \$\end{array}$<smiles>O=C(O)c1cn(C2CC2)c2cc(N3CCNCC3)c(F)cc2c1=O</smiles>

Ciprofloxacin / Cipro $\begin{array}{ll} & \text { Bayer } \\ \text { Indication: } & \text { Antibacterial } \\ \text { Sales 1997: } & \text { 1.44 Bio \$ }\end{array}$

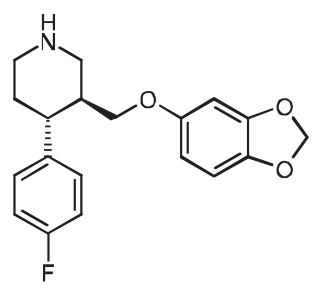

Paroxetine $/$ Paxil $^{\odot}$ Smith Kline Beecham Indication: Antidepressant Sales 1997: $\quad$ 1.47 Bio $\$$

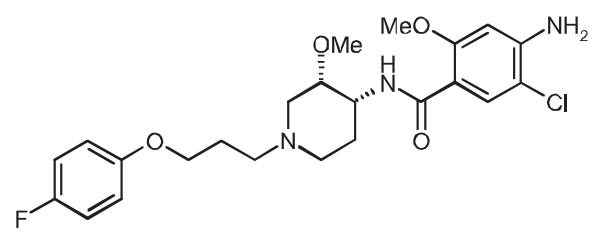

$$
\begin{array}{ll}
\multicolumn{2}{c}{\begin{array}{c}
\text { Cisaprid / Propulsid } \\
\text { Johnson }
\end{array}} \\
\text { Indication: } & \text { Pohnson } \\
\text { Salestaltic stimulant } \\
\text { Sales 1997: } & \text { 1.05 Bio \$ }
\end{array}
$$

Fig. 7. Best selling prescription drugs containing fluorine

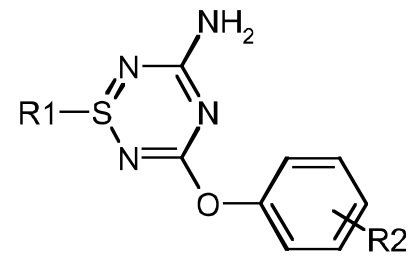

Herbicidal Thiatriazines

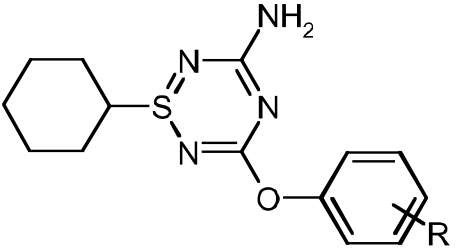

$\mathrm{R}=\mathrm{H}$

CGA 288' 821

$\mathrm{R}=2,5-\mathrm{F}_{2} \quad$ CGA $318^{\prime} 370$

$\mathrm{R}=\mathrm{F}_{5} \quad$ CGA $325^{\prime} 615$

Fig. 8.Structures of thiatriazines with herbicidal activity

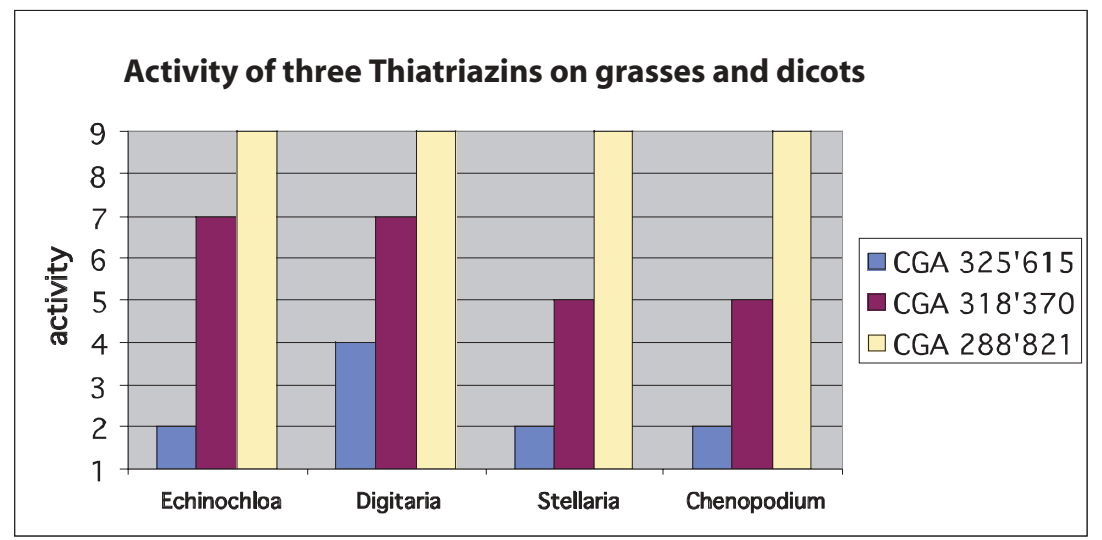

Visual evaluation 21 DAA: Rating $1-9 ; 1=100 \%$ control, 9= $0 \%$ control

Fig. 9. Herbicidal activity of thiatriazines CGA $325^{\prime} 615$, CGA 318 '370 and CGA 288' 821 (DAA: days after application)

mercial status as crop-protection products and pharmaceutical drugs has been observed, and the influence of fluorine on compounds in development in both areas is also increasing. The development of novel methods for incorporating fluorine into organic molecules as well as the commercial availability of novel fluorine-containing building blocks will no doubt continue to increase this number.

The incorporation of fluorine into a biologically active compound alters the electronic, lipophilic and steric properties and can critically increase the biological activity, the chemical and metabolic stability, and the bioavailability in many cases. To further exploit the unique potential of fluorine one needs to gain further insight into the fundamental aspects of fluoro-organic chemistry, in particular in the areas of structural, chemical, physico-chemical, and biological properties of fluorine-containing compounds.

\section{Acknowledgement}

We wish to thank Sohail Mirza, Heinz Binder and Hans-Peter Buser for providing information on crop-protection compounds proposed for ISO common names; Fredrik Cederbaum, Jean Wenger and Thomas Pitterna for helpful suggestions and critical review of this paper, as well as Prof. Antonio Togni for stimulating discussions.

Received: February 19, 2004

[1] J.T. Welch, S. Eswarakishanan, 'Fluorine in Bioorganic Chemistry', Wiley, New York, USA, 1991; and literature cited therein.

[2] T. Hiyama, 'Organofluorine Compounds: Chemistry and Applications', Springer, Berlin, Germany, 2000; and literature cited therein.

[3] G.T. Newbold, in 'Organofluorine Compounds and their Industrial Applications', Ed. R.E. Banks, Ellis Horwood, London, U.K., 1979, p. 169.

[4] The Agrochemical Handbook, 2nd ed., The Royal Society of Chemistry, London, U.K., 1988.

[5] Enigma Marketing Research, 1999.

[6] R. W. Lang, ACS Monograph 187 (Chemistry of Organic Fluorine Compounds II), 1995, 187, 1143-1147.

[7] D. Cartwright, Organofluorine Chem. 1994, 237-62.

[8] D.M. Ismail, J. Fluorine Chem. 2002, 118, 27-33.

[9] B.K. Park, N.R. Kitteringham, P.M. O'Neill, Annual Review of Pharmacology and Toxicology 2001, 41, 443-470.

[10] W. Bernhagen, Speciality Chemicals Magazine 1994, 14, 256-262.

[11] A. Becker, 'Inventory of Industrial FluoroBiochemicals', Eyrolles, Paris, FR, 1997.

[12] Med. Ad. News, Publisher: Engel Publishing Partners, West Trenton, NJ, USA, 1998, 17 (5), 14.

[13] B.E. Smart, J. Fluorine Chem. 2001, 109, $3-11$. 


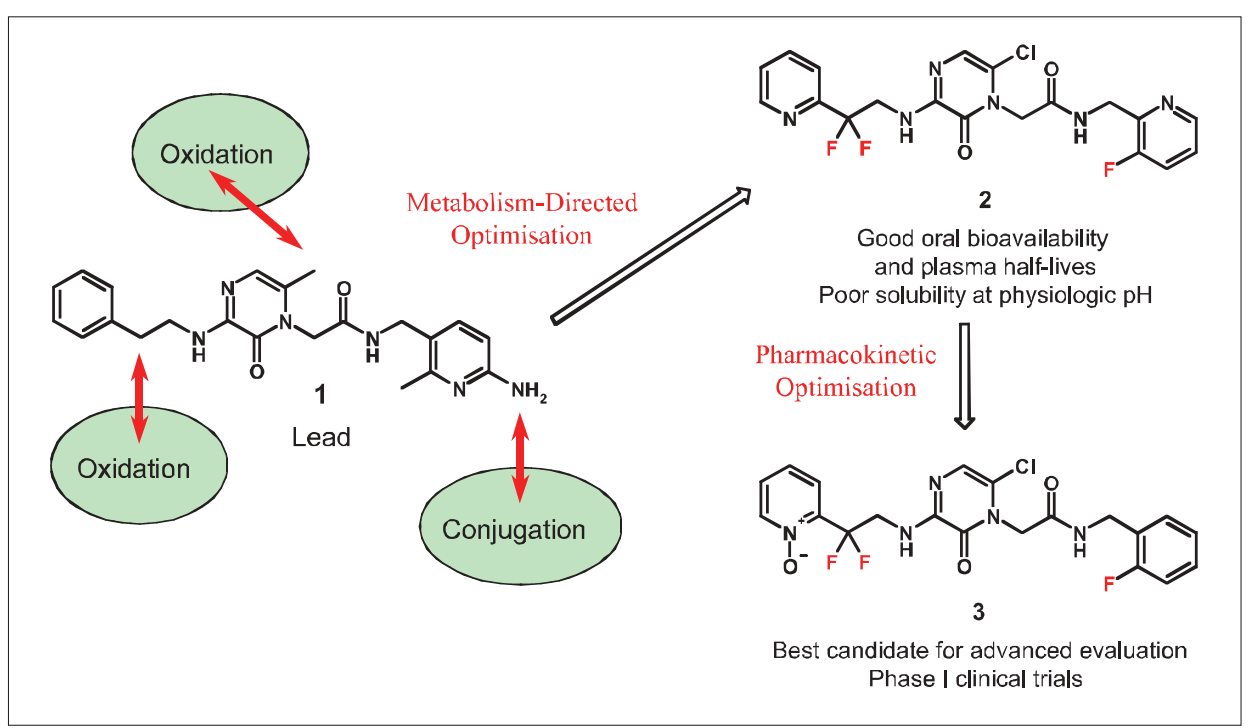

Fig. 10. 3-Aminopyrazinone thrombin inhibitors with increased metabolic stability

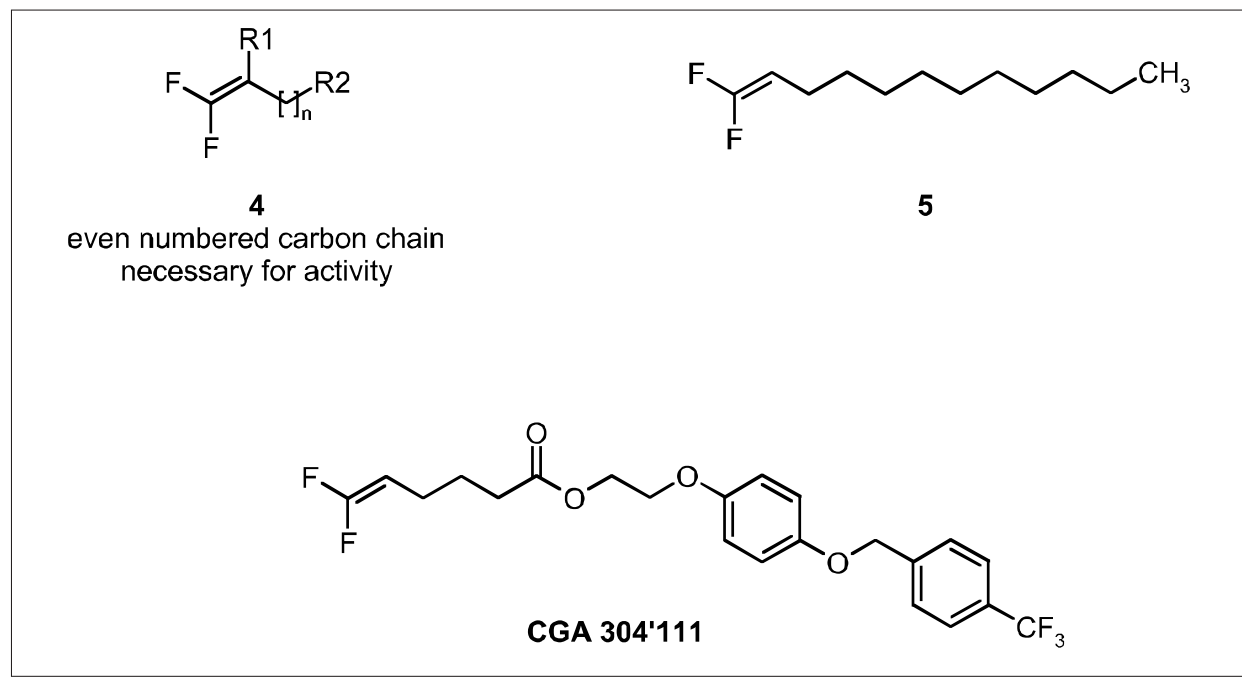

Fig. 11. gem-Difluorovinyl derivatives as insecticides and acaricides

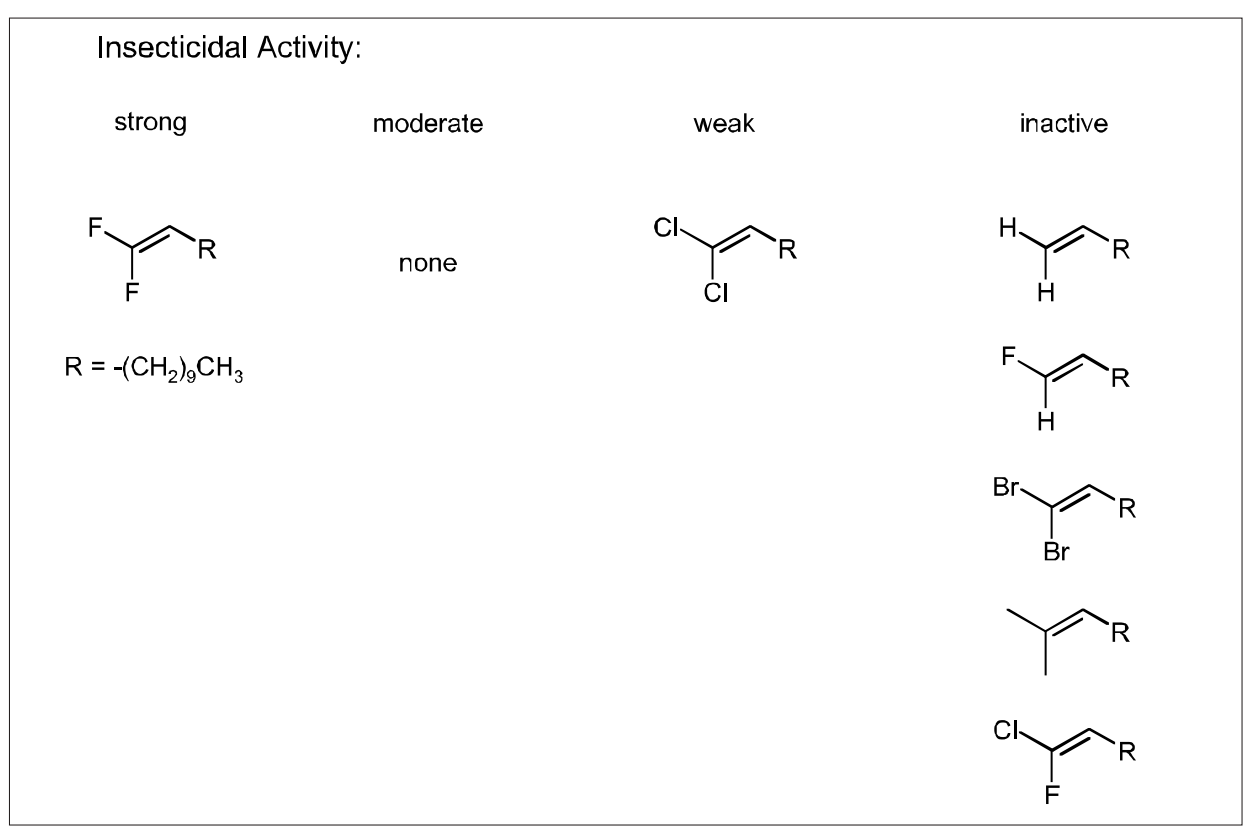

Fig. 12. Insecticidal activity of gem-difluorovinyl derivatives and analogues with modified pharmacophore
[14] M. Schlosser, in, 'Enantiocontrolled Synthesis of Fluoro-Organic Compounds', Ed. V.A. Soloshonok, John Wiley \& Sons Ltd., Chichester, UK, 1999, p. 613-659.

[15] P.H. Olesen, Current Opinion in Drug Discovery \& Development 2001, 4, 471-478.

[16] G.A. Patani, E.J. LaVoie, Chemical Reviews 1996, 96, 3147-3176.

[17] A. Burger, Progress in Drug Research 1991, 37, 287-371.

[18] K.B. Wiberg, P.R. Rablen, J. Am. Chem. Soc. 1993, 115, 614-25.

[19] W.T. Borden, Chem. Commun. 1998, 1919-1925.

[20] A. Stoller, K. Kreuz, M. Haake, J. Wenger, Chimia 2003, 57, 725-730.

[21] A.D. Stoller, J. Heterocyl. Chem. 2000, 37, 583-595.

[22] C.S. Burgey, K.A. Robinson, T.A. Lyle, et al, J. Med. Chem. 2003, 46, 461-473.

[23] C.S. Burgey, K.A. Robinson, T.A. Lyle, et al, Bioorg. \& Med. Chem. Lett. 2003, 13, 1353-1357.

[24] T. Pitterna, M. Böger, P. Maienfisch, Chimia 2004, 58, 108. 